\title{
Changes and Prognostic Value of Serum Vascular Endothelial Growth Factor in Patients with Differentiated Thyroid Cancer
}

\author{
Zhen-Hu Zhou ${ }^{a}$ Xiao-Ning Cui ${ }^{b}$ Huai-Guang Xing ${ }^{a}$ Rui-Hong Yan ${ }^{a}$ \\ Dao-Kuo Yao ${ }^{c}$ Le-Xin Wang ${ }^{b, d}$ \\ Departments of ${ }^{a}$ Nuclear Medicine and ${ }^{b}$ Cardiology, Liaocheng People's Hospital of Taishan Medical University, \\ Liaocheng, and 'Department of Cardiology, Beijing Friendship Hospital, Capital Medical University, \\ Beijing, China; ${ }^{d}$ School of Biomedical Sciences and Centre for Inland Health, Charles Sturt University, \\ Wagga Wagga, N.S.W., Australia
}

\section{Key Words}

Vascular endothelial growth factor $\cdot$ Thyroglobulin •

Thyroid $\cdot$ Cancer $\cdot$ Metastasis

\begin{abstract}
Objective: To evaluate the changes and the prognostic value of serum vascular endothelial growth factor (VEGF) in patients with differentiated thyroid cancer (DTC). Subjects and Methods: A total of 79 patients with DTC and 30 healthy individuals were divided into four groups: (1) a healthy control group ( $n=30)$; (2) DTC without recurrence $(n=35 ; 23$ papillary, 12 follicular); (3) DTC with local recurrence $(n=24 ; 15$ papillary, 9 follicular), and (4) DTC with lung metastasis ( $n=$ 20; 13 papillary, 7 follicular). Serum VEGF and thyroglobulin levels were measured in all patients. Results: Serum levels of VEGF were significantly higher in the lung metastasis group than in the other three groups $(p<0.05)$. Serum thyroglobulin concentration positively correlated with VEGF expression $(r=0.8678, p<0.001)$ in patients with thyroid cancer recurrence. Multivariate Cox regression analysis showed that clinical staging ( $O R=1.851,95 \% \mathrm{Cl} 1.04-3.47 ; \mathrm{p}=0.038)$, noncompliance with postoperative thyroxin replacement therapy $(\mathrm{OR}=1.935,95 \% \mathrm{Cl} 1.03-3.65 ; \mathrm{p}=0.042)$ and postoperative levels of thyroglobulin $(\mathrm{OR}=1.892,95 \% \mathrm{Cl} 1.01-3.56, \mathrm{p}=$
\end{abstract}

0.032) were independent predictors for thyroid cancer recurrence. Every additional $100 \mathrm{ng} / \mathrm{l}$ of serum VEGF levels increased the risk of thyroid cancer recurrence by $20.3 \%$; but this did not reach statistical significance $(O R=1.203,95 \% \mathrm{Cl}$ 0.95-1.52; $p=0.125$ ). Conclusions: Serum VEGF increased in patients with recurrent thyroid cancer following surgical therapies. The predictive value of serum VEGF requires further investigation.

Copyright $\odot 2012$ S. Karger AG, Basel

\section{Introduction}

Differentiated thyroid cancer (DTC) is one of the most common head and neck cancers. Although many patients can survive after surgery and radioactive iodine treatment, some experience tumor recurrence or metastases [1]. Efforts have been made to develop biomarkers to predict cancer recurrence in order to facilitate early prevention or treatment of DTC. Several studies have demonstrated that there is a correlation between tumor growth or metastases and microvessel formation in DTC $[2,3]$. Vascular endothelial growth factor (VEGF) is a glycoprotein that promotes endothelial regeneration, stimulates collateral blood vessel formation and increases vascular

\section{KARGER}

Fax +4161306 1234

E-Mail karger@karger.ch

www.karger.com
(C) 2012 S. Karger AG, Basel

1011-7571/13/0221-0024\$38.00/0

Accessible online at:

www.karger.com/mpp
Prof. Lexin Wang

School of Biomedical Sciences

Charles Sturt University

Wagga Wagga, NSW 2678 (Australia)

Tel. +61 26933 2905, E-Mail lwang@csu.edu.au 
permeability [4]. Recent studies have shown that tumor recurrence was related to tumor angiogenesis and VGEF was closely related to angiogenesis and growth invasion of thyroid papillary carcinoma [5]. High levels of serum VEGF and increased tissue expression of VEGF have been reported in patients with DTC [6-9]. Some studies have shown that the increase in serum VEGF correlates with local and distant metastasis in patients with thyroid cancer, and VEGF can be considered as an index of the presence of metastasis [5, 10-13]. However, another study showed that VEGF was decreased in patients with DTC [14]. Thyroglobulin measurement is primarily used to monitor DTC recurrence [15]. To date, there is limited data on the relationship between VEGF and thyroglobulin in patients with DTC, and the value of serum VEGF in predicting DTC recurrence following surgical therapy is uncertain. Therefore the aim of this study was to evaluate the changes in serum VEGF and their prognostic value for local and lung metastasis in patients with DTC.

\section{Subjects and Methods}

\section{Patient Selection}

The study was approved by the Ethics Committee of our hospital and informed written consent was obtained from all study participants. From March 2005 to September 2010, 79 consecutive patients with DTC were selected from the Department of Nuclear Medicine of our hospital. There were 53 women and 26 men, with a mean age of $39.5 \pm 11.5$ years (range, 16-68). Patients with the following conditions were excluded: (a) autoimmune disease; (b) coexistence of other cancers in addition to DTC; (c) pregnancy; (d) positive thyroglobulin antibody.

Physical exam, biopsy, and imaging tests (ultrasound, CT scan, MRI, chest X-ray, and nuclear medicine scans) were performed in each patient before surgery to assist with clinical staging of the DTC. The TNM staging system was used for preoperative staging. All patients were treated with thyroid resection, followed by radioiodine $\left({ }^{131} \mathrm{I}\right)$ treatment $(80-120 \mathrm{mCi}$, median $100 \mathrm{mCi}$ ) in our department to destroy the postoperative residual thyroid tissues. In patients with local or distant metastasis, an additional course of ${ }^{131} \mathrm{I}$ treatment $(120-150 \mathrm{mCi}$ for local recurrence, and 150-200 $\mathrm{mCi}$ for distant recurrence) was administered 3 months after the first ${ }^{131}$ I therapy. Thyroxin replacement therapy was prescribed to all patients following ${ }^{131} \mathrm{I}$ therapy.

In addition, a control group $(\mathrm{n}=30)$ was recruited from the patients who presented for thyroid biopsy, whose thyroid was normal in tissue biopsy, thyroid ultrasonography and thyroid function tests. There were 19 women and 11 men, with a mean age of $40.8 \pm 10.6$ years (range, $19-65$ years).

\section{Specimen Collection and Testing}

Fasting venous blood samples $(5 \mathrm{ml})$ were collected in all patients after surgery and before ${ }^{131} \mathrm{I}$ therapy. Serum was separated and kept at $-40^{\circ} \mathrm{C}$ in a refrigerator until analysis. Serum VEGF levels were measured by enzyme-linked immunosorbent assay with a commercially available human VEGF kit (Hailang Biotechnology Co., Ltd., China). First, serum samples and standards were incubated with murine anti-VEGF monoclonal antibodies for $2 \mathrm{~h}$, before enzyme-linked anti-VEGF polyclonal antibodies were added. Tetramethylbenzidine was used to display the intensity of the reactions. Optical density was measured at $450 \mathrm{~nm}$ using a VMax microplate reader and Softmax Pro software (Molecular Devices, Menlo Park, Calif., USA). All samples were run in duplicate, and a standard curve was established for each assay. Thyroid-stimulating hormone (TSH), thyroglobulin and thyroglobulin antibody concentrations were detected by chemiluminescence immunoassay methods (Beckman kits, USA). All samples of TSH and thyroglobulin were run in duplicates.

\section{Follow-Ups}

Neck ultrasound and chest CT studies were performed at 3,6 and 12 months after ${ }^{131} \mathrm{I}$ treatment. Patients were divided into three groups: no recurrence, local recurrence and lung metastasis. Local recurrence was confirmed by fine-needle aspiration biopsy, and lung metastasis was confirmed by chest $\mathrm{CT}$ as well as ${ }^{131} \mathrm{I} \mathrm{im-}$ aging studies.

\section{Statistics}

Continuous data was expressed as mean \pm SD. Student's t test was used for comparison of data between groups. Spearman rank correlation analysis was used for the correlation study between serum VEGF and serum thyroglobulin concentrations. Cox regression analysis was applied for multivariate analysis of recurrence; $\mathrm{p}<0.05$ was considered as statistically significant. SPSS 10.0 statistical package (Chicago, Ill., USA) was used for statistical analysis.

\section{Results}

\section{Follow-Up}

In DTC patients, 51 had papillary carcinoma and 28 had follicular carcinoma. There was no statistically significant difference in age and sex between the DTC and control groups $(\mathrm{p}>0.05)$. The follow-up time was between 12 and 72 months (mean $44.3 \pm 4$ months, median 47). A single course of ${ }^{131}$ I treatment was applied to 23 patients. In the remaining patients with local or distant recurrence, $2,3,4$ and 5 courses of ${ }^{131}$ I therapy were applied to 12, 20, 18 and 6 patients, respectively. During follow-up, 4 patients had reoperation due to continued cervical lymph node enlargement. Two other patients also had cervical lymph node enlargement but were treated palliatively as the cervical lymph node and vascular adhesion were too extensive to be operated on. In addition, 2 patients died of pulmonary metastasis. Overall, 35 patients (23 papillary, 12 follicular) had no recurrence, 24 (15 of papillary, 9 of follicular) had local recurrence, and 20 (13 of papillary, 7 of follicular) had lung metastasis. 
Table 1. Comparison of postoperative serum thyroglobulin and VEGF levels among groups

\begin{tabular}{|c|c|c|c|c|c|}
\hline & $\begin{array}{l}\text { Lung metastasis } \\
(\mathrm{n}=20)\end{array}$ & $\begin{array}{l}\text { Local recurrence } \\
(\mathrm{n}=24)\end{array}$ & $\begin{array}{l}\text { Without recurrence } \\
(\mathrm{n}=35)\end{array}$ & $\begin{array}{l}\text { Control } \\
(\mathrm{n}=30)\end{array}$ & $\mathrm{p}$ \\
\hline Age (median), years & 38 & 41 & 34 & 43 & $>0.05$ \\
\hline Male & $4(20 \%)$ & $9(37.5 \%)$ & $13(37.1 \%)$ & $11(36.7 \%)$ & $>0.05$ \\
\hline $\mathrm{TSH}, \mathrm{mIU} / \mathrm{l}$ & $2.16 \pm 0.80$ & $2.03 \pm 0.76$ & $2.07 \pm 0.68$ & $2.12 \pm 0.89$ & $>0.05$ \\
\hline Thyroglobulin, $\mu g / 1$ & $77.52 \pm 63.82^{*}$ & $35.35 \pm 24.31^{*}$ & $1.27 \pm 0.86$ & & \\
\hline VEGF, pg/ml & $736.5 \pm 248.2^{*}$ & $407.8 \pm 57.6^{*}$ & $284.7 \pm 48.8$ & $268.6 \pm 36.9$ & $<0.05$ \\
\hline
\end{tabular}

${ }^{*} \mathrm{p}<0.01$ compared with the nonrecurrence group and the control group.

Table 2. Comparison of postoperative serum VEGF in papillary and follicular thyroid cancer in the study groups

\begin{tabular}{llll}
\hline Groups & Papillary carcinoma $(\mathrm{n})$ & Follicular carcinoma (n) & $\mathrm{p}$ \\
\hline Lung metastasis & $721.9 \pm 308.5(13)$ & $756.0 \pm 202.6(7)$ & 0.80 \\
Local recurrence & $400.8 \pm 57.9(15)$ & $435.8 \pm 57.8(9)$ & 0.16 \\
Without recurrence & $283.5 \pm 51.7(23)$ & $289.9 \pm 35.2(12)$ & 0.70 \\
\hline
\end{tabular}

Table 3. Multivariate Cox regression analysis of predicting factors for thyroid cancer relapse

\begin{tabular}{lll}
\hline & OR $(95 \%$ CI $)$ & $\mathrm{p}$ \\
\hline Sex & $1.404(0.63-3.13)$ & 0.408 \\
Age & $0.996(0.99-1.03)$ & 0.822 \\
Clinical staging & $1.851(1.04-3.47)$ & 0.038 \\
Pathological types & $1.373(0.96-2.48)$ & 0.277 \\
Noncompliance with thyroxin therapy & $1.935(1.03-3.65)$ & 0.042 \\
Thyroglobulin & $1.892(1.01-3.56)$ & 0.032 \\
VEGF & $1.203(0.95-1.52)$ & 0.125 \\
\hline
\end{tabular}

\section{Comparison of Serum Thyroglobulin and VEGF}

Levels among Study Groups

The sensitivity of the VEGF assay was $<7.0 \mathrm{pg} / \mathrm{ml}$, with inter- and intra-assay variations of $<5 \%$, while the sensitivity of TSH and thyroglobulin assays was $<0.1 \mathrm{mIU} / 1$ and $1.0 \mu \mathrm{g} / \mathrm{l}$, respectively, with $<5 \%$ inter- and intra-assay variations for both. In our laboratory, the reference range for TSH was $0.3-3.0 \mathrm{mIU} / \mathrm{l}$, and for thyroglobulin it was 1.0-27.0 $\mu \mathrm{g} / \mathrm{l}($ mean $5.0 \mu \mathrm{g} / \mathrm{l})$.

As shown in table 1, serum TSH levels were normal in all patients and there was no significant difference in serum TSH levels between the groups. The serum thyroglobulin concentration in the lung metastasis group was higher than in the local recurrence and the nonrecurrence group $(\mathrm{p}<0.01)$. The serum VEGF level in the lung metastasis group was higher than in the other three groups $(\mathrm{p}<0.01)$. There was no statistically significant difference in serum VEGF levels between the nonrecurrent and the control group ( $\mathrm{p}>0.05)$. There was no statistically significant difference in serum VEGF levels in patients with different pathological types of DTC (table 2, $\mathrm{p}>0.05)$. Correlation analysis showed that in patients with recurrent DTC, serum VEGF concentration positively correlated with thyroglobulin concentration $(\mathrm{r}=$ $0.8678, \mathrm{p}<0.001$ ).

\section{Factors of Thyroid Cancer Recurrence after Surgery}

Six variables including gender, age, clinical stage (I, II or III), histological type (papillary or follicular), serum VEGF levels (every additional 100-ng/l assignment), and thyroglobulin levels have been taken into the multivariate Cox regression model. The multivariate Cox regression analysis showed that clinical staging $(\mathrm{OR}=1.851,95 \%$ CI $1.04-3.47 ; \mathrm{p}=0.038)$ and thyroglobulin levels $(\mathrm{OR}=1.892,95 \%$ CI $1.01-3.56, \mathrm{p}=0.032)$ were independent predictors for thyroid cancer recurrence (table 3). Noncompliance with postoperative thyroxin treatment was also an independent predictor for recurrence $(\mathrm{OR}=1.935,95 \%$ CI $1.03-3.65, \mathrm{p}=0.042)$. Every additional $100 \mathrm{ng} / \mathrm{l}$ of serum VEGF levels in- 
creased the risk of thyroid cancer recurrence by $20.3 \%$; but this did not reach statistical significance $(\mathrm{OR}=$ $1.203,95 \%$ CI $0.95-1.52 ; \mathrm{p}=0.125$, table 3 ).

\section{Discussion}

Our study showed that in patients with postoperative recurrence of DTC, there was an elevated serum level of VEGF. The level of VEGF in patients with lung metastasis was higher than in those with local recurrence. This study also showed that the serum level of VEGF in patients with recurrent DTC correlated with serum thyroglobulin levels. Furthermore, clinical staging, noncompliance with postoperative thyroxin therapy and serum thyroglobulin, but not serum VEGF, were independent predictors for the postoperative recurrence of DTC. These results suggest that although there was an increase in serum VEGF in patients with recurrent DTC, its value in predicting the prognosis of DTC requires further investigation.

It was reported that in patients with newly diagnosed thyroid cancer, serum VEGF levels were higher, but the postoperative serum VEGF level was reduced to normal [13]. However, previously reported serum VEGF concentrations in patients with thyroid cancer and the value of VEGF in predicting postoperative prognosis have been inconsistent [5-9, 10-14]. These inconsistencies may be related to the types of thyroid cancer, as different pathological types of thyroid cancer cells vary in their capacity to produce VEGF, and undifferentiated thyroid cancer and tumor cells produce more VEGF than other types [9-21]. The degree of differentiation of thyroid cancer was also related to the level of serum VEGF concentration $[21,22]$. In the present study, however, the types of DTC (papillary or follicular) did not seem to have a significant impact on the serum VEGF levels, as the mean serum VEGF concentrations were similar between the two types of thyroid cancer (table 3). A significant difference in serum VEGF concentrations was found between patients with recurrence or nonrecurrence, suggesting that the recurrence of carcinoma is a major determining factor of postoperative VEGF levels.

At present, the serum thyroglobulin concentration is considered the most sensitive means of recurrence monitoring in thyroid cancer [15]. However, the serum thyroglobulin concentration is often subject to interference of thyroglobulin antibodies, leading to false-negative occurrence. Our study showed that in patients with lung metastasis and local recurrence, both the serum thyroglobulin concentration and serum VEGF were increased, and there was a linear correlation between the two. Every additional $100 \mathrm{ng} / \mathrm{l}$ of serum VEGF levels increased the risk of thyroid cancer recurrence by $20.3 \%$. However, multivariate regression analysis failed to show that VEGF was able to predict the recurrence of DTC. These results suggest that serum VEGF measurement may be used as a biomarker of thyroid cancer recurrence, but its interpretation must be in conjunction with other predictors such as clinical staging and serum thyroglobulin levels.

The most appropriate timing for blood sampling and VEGF assay in patients with DTC requires further investigation. It is possible that serum VEGF measured prior to thyroid surgery might have given better differentiation in outcome prediction. However, as the thoroughness of cancer resection and unsuspected residual disease also determine the outcomes of surgery, postoperative serum VEGF might be a better indicator of residual disease burden, and a better predictor of medium- to long-term prognosis.

\section{Conclusions}

In patients with recurrent DTC, serum VEGF was elevated and positively correlated with serum thyroglobulin. Serum VEGF may be used as a biomarker in addition to thyroglobulin for the assessment of the postoperative prognosis of DTC.
References
1 Milano A, Chiofalo MG, Basile M, Salzano de Luna A, Pezzullo L, Caponigro F: New molecular targeted therapies in thyroid cancer. Anticancer Drugs 2006;17:869-879.

-2 Dhar DK, Kubota H, Kotoh T, Tabara H, Watanabe R, Tachibana M, Kohno H, Nagasue N: Tumor vascularity predicts recurrence in differentiated thyroid carcinoma. Am J Surg 1998;176:442-447.

\footnotetext{
3 Segal K, Shpitzer T, Feinmesser M, Stern Y, Feinmesser R: Angiogenesis in follicular tumors of the thyroid. J Surg Oncol 1996;63: 95-98.

4 Ishiwata I, Sudo T, Kiguchi K, Ishikawa H: Tumor angiogenesis factors produced by cancer cells. Hum Cell 1999;12:37-46.
} 
5 Hsueh C, Lin JD, Wu IC, Chao TC, Yu JS, Liou MJ, Yeh CJ: Vascular endothelial growth factors and angiopoietins in presentations and prognosis of papillary thyroid carcinoma. J Surg Oncol 2011;103:395-399.

-6 Viglietto G, Maglione D, Rambaldi M, Cerutti J, Romano A, Trapasso F, Fedele M, Ippolito P, Chiappetta G, Botti G, et al: Upregulation of vascular endothelial growth factor (VEGF) and downregulation of placenta growth factor (PLGF) associated with malignancy in human thyroid tumors and cell lines. Oncogene 1995;11:1569-1579.

-7 Tuttle RM, Fleisher M, Francis GL, Robbins RJ: Serum vascular endothelial growth factor levels are elevated in metastatic differentiated thyroid cancer but not increased by short-term TSH stimulation. J Clin Endocrinol Metab 2002;87:1737-1742.

8 Soh EY, Duh QY, Sobhi SA, Young DM, Epstein HD, Wong MG, Garcia YK, Min YD, Grossman RF, Siperstein AE, Clark OH: Vascular endothelial growth factor expression is higher in differentiated thyroid cancer than in normal or benign thyroid. J Clin Endocrinol Metab 1997;82:3741-3747.

-9 Sherman SI, Wirth LJ, Droz JP, Hofmann M, Bastholt L, Martins RG, Licitra L, Eschenberg MJ, Sun YN, Juan T, Stepan DE, Schlumberger MJ: Motesanib diphosphate in progressive differentiated thyroid cancer. $\mathrm{N}$ Engl J Med 2008;359:31-42.

10 Yu XM, Lo CY, Chan WF, Lam KY, Leung P, Luk JM: Increased expression of vascular endothelial growth factor $\mathrm{C}$ in papillary thyroid carcinoma correlates with cervical lymph node metastases. Clin Cancer Res 2005;11:8063-8069.
Klubo-Gwiezdzinska J, Junik R, Kopczynska E, Juraniec O, Kardymowicz H: The comparison of serum vascular endothelial growth factor levels between patients with metastatic and non-metastatic thyroid cancer, and patients with nontoxic multinodular goiter. Eur J Endocrinol 2007;157:521-527.

12 Karaca Z, Tanriverdi F, Unluhizarci K, Ozturk F, Gokahmetoglu S, Elbuken G, Cakir I, Bayram F, Kelestimur F: VEGF1 expression is related to lymph node metastasis and serum VEGF may be a marker of progression in the follow-up of patients with differentiated thyroid carcinoma. Eur J Endocrinol 2011;164:277-284.

13 Yu XM, Lo CY, Lam AK, Leung P, Luk JM: Serum vascular endothelial growth factor C correlates with lymph node metastases and high-risk tumor profiles in papillary thyroid carcinoma. Ann Surg 2008;247:483-489.

14 Nersita R, Matrone A, Klain M, Scavuzzo F, Vitolo G, Abbondanza C, Carlino MV, Giacco V, Amato G, Carella C: Decreased serum vascular endothelial growth factor-D levels in metastatic patients with differentiated thyroid carcinoma. Clin Endocrinol (Oxf) 2012;76:142-146.

15 Spencer CA, LoPresti JS, Fatemi S, Nicoloff JT: Detection of residual and recurrent differentiated thyroid carcinoma by serum thyroglobulin measurement. Thyroid 1999;9: 435-441.

6 Karayiannakis AJ, Syrigos KN, Polychronidis A, Zbar A, Kouraklis G, Simopoulos C, Karatzas G: Circulating VEGF levels in the serum of gastric cancer patients: correlation with pathological variables, patient survival, and tumor surgery. Ann Surg 2002;236:3742.
17 Mitsuhashi A, Suzuka K, Yamazawa K, Matsui H, Seki K, Sekiya S: Serum vascular endothelial growth factor (VEGF) and VEGF$\mathrm{C}$ levels as tumor markers in patients with cervical carcinoma. Cancer 2005; 103:724730.

18 Tamura M, Ohta Y: Serum vascular endothelial growth factor-C level in patients with primary nonsmall cell lung carcinoma: a possible diagnostic tool for lymph node metastasis. Cancer 2003;98:1217-1222.

19 Katoh R, Miyagi E, Kawaoi A, Hemmi A, Komiyama A, Oyama T, Shibuya M: Expression of vascular endothelial growth factor (VEGF) in human thyroid neoplasms. Hum Pathol 1999;30:891-897.

20 Viglietto G, Romano A, Manzo G, Chiappetta G, Paoletti I, Califano D, Galati MG, Mauriello V, Bruni P, Lago CT, Fusco A, Persico MG: Upregulation of the angiogenic factors PlGF, VEGF and their receptors (Flt-1, Flk-1/KDR) by TSH in cultured thyrocytes and in the thyroid gland of thiouracil-fed rats suggest a TSH-dependent paracrine mechanism for goiter hypervascularization. Oncogene 1997;15:2687-2698.

21 Itoh $\mathrm{A}$, Iwase $\mathrm{K}$, Jimbo $\mathrm{S}$, Yamamoto $\mathrm{H}$, Yamamoto N, Kokubo M, Senda T, Nakai A, Nagagasaka A, Nagasaka T, Hibi Y, Seko T: Expression of vascular endothelial growth factor and presence of angiovascular cells in tissues from different thyroid disorders. World J Surg 2010;34:242-248.

22 Sherman SI: Targeted therapies for thyroid tumors. Mod Pathol 2011;24(suppl 2):S44S52. 